\title{
RESENHAS
}

\section{Memória Política de um Tempo Recente}

\section{Ana Cleide C. Cesário}

ReIs, F.W. Tempo Presente: do MDB a FHC. Belo Horizonte: Editora UfMg, 2002. 403 p.

Ler Tempo Presente: do MDB a FHC, de Fábio Wanderley Reis, édebruçar-se sobre um conjunto de mais de uma centena de artigos assinados pelo cientista político e publicados em diversos jornais do país: Estado de S.Paulo, Folba de S.Paulo, Jornal da Tarde, Jornal do Brasil e O Tempo. Sobre a organizaçãoda obra, o autor diz ter separado os artigos "sob algumas categorias amplas de assuntos, dispondo-os simplesmente em ordem cronológica dentro de cada categoria", apresentando-os em cinco partes: Autoritarismoe transição; Democracia, eleitoradoe reformas; Nação brasileira e questão social; Cena mundial e Globalização; Governo FHC e oposição. Como Epílogo, o autor selecionou um único artigo intitulado Ir para casa em paz. Trata-se de obra remissiva em que os artigos versam sobre política nacional e externa, durante o último quarto de século, período internamentemarcado peloprocesso de transição do autoritarismo para a democraciae, internacionalmente, pela "financeirização" da acumulação capitalista em escala mundial, associada ao desenvolvimento tecnológico que levaramà globalizaçãoe pelo declíniodo socialismo que, encerrando o período da Guerra Fria, afirmou aindamais os Estados Unidoscomopaís hegemônioo nocenário mundial.
Diante desses dois cenários e das condições de produção decorrentes do encontro da história com as ideologias, 0 analista produziu um conjunto de textos sobre os mais diferentes temas e acontecimentos da política nacional: partidos, eleições, eleitorado e as questões polêmicas decorrentes da agenda de reformas institucionais; democracia, estado e república; temas referentes à relação público e privado; análise de atores políticos como Ulysses, Tancredo, Collor, FHCe Lula e de suas participações no ciclo de estabilidade e crise que marcou a vida política do país durante o período. Importantes são os temas relacionados à nação brasileira à questão social como: o nacional e o global, violência, exclusão, minorias, racismo e ação afirmativa . Há ainda um conjunto de artigos sobre o governo FHC e a oposição que lhe foi feita, focalizando temas que já antecipavam o que hoje Fábio Wanderley Reis denomina de uma "polaridade entre PT e PSDB", partidos avaliados por ele como progressistas e que tendem, do ponto de vista ideológico, a reforçar o "centro", inviabilizando, em períodos eleitorais, extremismos de direita ou de esquerda. (Ver entrevista do autor neste número de Mediações). No referente ao cenário internacional, o livro 
apresenta análises sobre política externa e economia mundial, o Consenso de Washington, os episódios de Seattle, a Terceira Via e o 11 de setembro de 2001.

Apresentar os artigos simplesmente agrupados portemas, mesmo que referidos a "categorias amplas de assuntos", talvez não seja suficiente para queo leitor perceba o que há de comum entre eles e quais são os elementos que lhes dão unidade. É importante que o leitor atente para uma observação feita pelo autor, em nota introdutória do livro, sinalizando que "os artigos têm em comum, na grande maioria dos casos, a característica de procurarem trazer uma perspectiva analítica à discussão sobre aspectos salientes da conjuntura". Exemplo dissoé a percepção que se tem, quando se lê os artigos sobre a política nacional, da preponderância do MDB como partido que originariamente expressou os anseios democráticos dasociedade brasileira, concentrando ações políticas que tornaram possível o processo de abertura, conduzindo o país, do autoritarismo com sistema bipartidário, para a consolidaçãodeumademocracia representativa de sistema pluripartidário..

Seriam estas indicações suficientes para a compreensão de uma obra tão vasta, compostade artigos tão variados sobre um período marcado por episódios de significados densos e emblemáticos? Atentar para as condições de produção dos artigos, ou seja, a disposição do intelectual em inscrever suas análises e reflexões na formação discursiva jornalística, permite ao leitor apreender as especificidades de um trabalho que, respaldado por umasólida formação acadêmica, dirige-se ao grande público, incitando o debate político. Identificar, nos artigos, vestígios de algumas questões de amplo alcance quehámuitovêm perpassando os trabalhos de cunho teórico-analítico do autor, constitui uma tarefa de leitura "investigativa", recompensada pela descoberta de conexões entre os textos. Aintenção não é reduzir a leitura do livro a dois tipos de olhares apenas, massugerir dois lugares estratégicos de interpretação dos vários sentidos da obra. Nãose trata de buscar novas tendências e contribuições do autor para o que, geralmente, se convenciona chamarde conjuntode sua obra. 0 que sepretende ésimplesmente, por meio de pré-construídos e do interdiscurso do próprio autor, colocar em relevo elementos que conferem unidade aos textos do livro que, devido àsuanatureza, aparenta fragmentação.

No tocante às condições e ao processo de produção, Tempo Presente revela uma disposição de Fábio Wanderley Reis em se colocar num lugar de escuta e de autoria onde se torna possivvel a interpretação da política em tempo quase que simultâneo ao dos acontecimentos, 0 tempo que regula o trabalho jornalístico e a formação discursiva do jornal. Trata-se, portanto, de uma obra produzida no ardor das contendas políticas, muitas vezes, sem as condições usuais de que dispõe o pesquisador no seu ambiente acadêmico, onde desfruta de um certo distanciamento dos acontecimentos e das questões ideológicas que os acompanham.

Exemplo desse envolvimento é o artigo intitulado "A democracia brasileira e eu", publicado no jornal 0 Tempo, em resposta a uma celeuma provocada por outro texto do autor, intitulado Brasil ao quadrado, escrito para o Forum Nacional de 2001, organizado pelo exministro João Paulo Velloso, no Rio de Janeiro, ano que precedia a eleição presidencial. Por ter sido distribuído por Olavo Setubal a empresários em um jantar em que se encontrava o presidente da República, o texto foi denunciado publicamente por políticos como parte de uma conspiração antidemocrática. No artigo "A democracia brasileira e eu", Fábio Wanderley Reis, após esclarecer sua posição em relação a uma possível vitória de Lula e a chegada do PT 
ao governo - uma vez que estes eram os principais pontos que alimentavam a polêmica -, assim se manifestou: “... alguma insegurança parece existir numa democracia em que passagens de certo texto de um vago professor podem, de repente, suscitar a celeuma que vimos estes dias".

Aleitura, não apenas deste artigo, mas de muitos que compõem o livro, mostra que o autor teve sempre a consciência do significado de escrever parajornaise dasua inserção no debate público do momento. Ao se ocupar da edição do livro e olhar seus artigos como análises de fatos de um passado recente à luz de seus desdobramentos, o autor assim se refere a eles: "Por certo, o leitor encontrará avaliações que retrospectivamente se mostram talvez de sustentação mais precária. Mas as verdades que o passar do tempo evidenciam são de pouca ajuda nas incertezas da conjuntura. E pode ser que haja o que aprender em olhar de novo 0 passado como presentededesdobramentos incertos".

Se, por um lado, um trabalho dessa natureza, se afasta dos cânones da análise acadêmica, por outro, produz uma importante memória política, por meio de textos que além de trazerem uma perspectiva analítica sobre aspectos conjunturais, estabelecem um processo de criação e funcionamento do discurso no qual não apenas o autor se faz presente mas também 0 agente político se insinua. Na nota introdutória já citada, 0 autor assim se expressa sobre 0 processo de produção dos artigos: "o empenho analítico se deixa impregnar mais fortemente pela perspectiva do cidadão e suas disposições de ordem não apenas intelectual". Não é por acaso que 0 artigo intitulado "Ir para casa em paz" é escolhido para o epílogo do livro, um texto em que Fábio Wanderley Reis se coloca não apenas como autor, mas sobretudo como sujeito que se constitui à medida que, por meio de sua produção intelectual e de suas preocupações de cidadão, assume a prática discursiva como um modo de agir politicamente.

No epílogo, o cidadão se mostra como um agente político que, após ter realizado um trajeto intelectual marcado pelos desafios e percalços que caracterizam a vida pública, reivindica "0 mais elementar dos direitos civis de querer ir para casa em paz", de se recolher à tranqüilidade da vida privada. No artigo que encerra o livro, os traços ideológicos do perfil de um intelectual conhecido pelas suas análises consistentes e provocativas - e que lhe deram 0 estatuto de um dos mais respeitados pesquisadores da área de ciência política no Brasil - são desenhados como esboço de um auto-retrato. É como se Fábio Wanderley Reis estivesse sugerindo aos leitores, em geral, e, em especial, aos seus pares da academia, que olhem o conjunto de artigos como uma linguagem capaz de revelar a figura de um cidadão de inspiração clássica e republicana que, movido pelo desejo de participar, defrontou-se com um país grandee desigual. Um país marcado por uma pesada herança escravista e incapaz de proporcionar à maioria de sua população o sentimento pleno de autonomia e civismo.

Revivendo 0 impulso de participação no espaço público o autor faz, no epílogo, um balanço de suas filiações ideológicas. Recorda que a adesão aos ideais igualitários do comunismo, por meio da instrumentalização do Estado, acabou por colocá-lo frente à repressão e à censura desencadeadas pelo Brasil de 64, admitindo que a experiência autoritária vivida no país levou-o a reconhecer a importância da democracia como garantia dos direitos civis e políticos básicos e condição de realização da igualdade social. Confessa o seu alívio pela superação de duas décadas de obscurantismo 
político e reconhece que sua conversão à social democracia se deu tardiamente, uma vez que as possibilidades de conformação de um Estado do bem-estar, para o país, são mínimas, em virtude da crise fiscal e da questão social que, no Brasil, apresenta-se "elevada ao quadrado", isto é, uma situação em que as desigualdades internas são potencializadas pelas regras de submissão da nova dinâmica mundial.

Diante das vacilações do governo e de um presidente intelectual que titubeia em suas convicções - que, em certa medida, parecem ter sido por ele compartilhadas-emovido pelo receio de se tornar um neoliberal acomodado realisticamente à essa moderna epoderosa lógica danova dinâmica mundial, Fábio Wanderley Reis clama pelo recolhimento da vida privada, dizendo renunciar a qualquer tomada de posição abrangente: "Confuso, agarro-me à afirmação fragmentária de certos valores mais ou menos comezinhos. Quero compostura nos agentes públicos...". 0 livro proporciona a descoberta de um tipo de discurso que pode significar tanto crítica e resignação, como expressar indignação, esperança, ou mesmo serenidade, expressões não propriamente de sentimentos do autor, mas sim de virtudes políticas. Suavasta experiência acumulada como observador e pesquisador de diferentes conjunturas, e a propriedade com quesempreformulou consistentes bases conceituais parasuas reflexões, garantiram a ele dar mostras, em seu livro, de como lidou com a situação pouco usual enfrentada pelo intelectual quando se dirige ao grande público por meio de jomais. Combinando sólida formação teórica com um estilo discursivo despojado, coloquial e contundente, o autor oferece um produto final que pode ser tanto de interesse do grande público leitor de jornal-seu primeiro destinatário - quanto para um grupo mais seleto de leitores acostumados com a análise política feita nas universidades, parcela para a qual o livro agora se destina.

Se até aqui este comentário ateve-se mais ao processo e às condições de produção, bem como às questões relacionadas à autoria e ao sujeito da práticadiscursiva, cabeneste momento aindagação do que haveria de pré-construído e de inter e intradiscursos formulados pelo próprio autor em outros trabalhos capazes de iluminar 0 entendimento desta obraem particular. 0 ponto de vista que se quer defender é o de que, mesmo ao escrever sobre temas e episódios do dia-a-dia da política, publicando-os em jornal, 0 autor esteve executando uma tarefa relacionada a algumas reflexões teóricas de grande alcance por ele mesmo formuladas. Esta obra constitui exemplo de que ele sempre esteve atento a um problema da Ciência Política identificado, em recente análise feita para a Folha de S.Paulo, "como a tensão entre o seu inevitável componente normativo que marca milenarmente a reflexão sobre a política, e o empenho de acuidade factual e rigor analítico, ou o empenho cientiffico", tensão que se torna ainda maior quando a análise se dá em condições muito próximas àquelas do trabalho jornalístico e midiático, de modo geral. Olhando o conjunto de textos, especialmente os que dizem respeito à política brasileira, identifica-se o tema central em torno do qual giraessa tensão: "as relações entre democracia e autoridade".

Tempo Presente é uma obra que permite a leitura de um implícito que lhe confere coerência e que é traduzido pelo autor como um dos temas fundamentais da política: "como preservar a autonomia das pessoas e prevenir as distorções autoritárias ou corruptas da busca (eficaz...) de objetivos comuns pelo Estado". 0 livro aponta para a dificuldade em substituir as turbulências e instabilidades políticas pela democracia e autonomia dos cidadãos, pois existe, em nosso país, uma questão social 
caracterizada por uma intensa desigualdade e um fosso social agravados pela situação de país periférico explorado pelo capital internacional. Ler Tempo presente à luz dessas reflexões de amplo alcance, oferecidas pelo próprio autor, $\mathrm{e}$ que ainda não haviam sido tão claramente explicitadas como foram agora mais recentemente, constitui um exercício interessante, pois permite encontrar trajetos discursivos no conjunto dos artigos que compõem o livro.

Tempo Presente pode ser visto como um livro dememóriapolíticaecomo partede uma memória discursiva jomalística. Por se tratar de uma coletânea de artigos publicados na imprensa, estabelece uma intertextualidade com vários jornais brasileiros, podendo se constituir como "porta de entrada" nesses jornais. Sabe-se que o texto jornalístico não é apenas formação discursiva, mas prática sociale política, pois funciona em várias dimensões temporais quando capta, interpreta e divulga acontecimentos, idéias e opiniões de uma atualidade. 0 jomal lêe registraum tempo presente, mas ao fazê-loécomo se organizasse um futuro já que perscruta as consequiências de fatos atuais, abrindo uma perspectiva de devir e, ao mesmo tempo, legitima uma memória aser lida no futuro.

A obra de Fábio Wanderley Reis sugere, especialmente a quem trabalha com o discurso político, a possibilidade de novas análises, não mais pela perspectiva do autor, mas pelo discurso, opiniões e posições políticas veiculadas e assumidas pelos jornais nos quais os artigos foram publicados. Tomando os jornais como objeto de investigação, abre-se, ao analista, 0 desafio de outras interpretações possíveis a respeito dos mesmos acontecimentos, a possibilidade de compreensão da formação ideológica de cada um desses periódicos, bem como dos sentidos por eles atribuídos aos acontecimentos políticos do período em questão. Desse modo, Tempo Presente pode ser uma fonte de inspiração para novas leituras sobre um passado recente. Afinal, como diz o próprio autor, "trata-se sobretudo de política, e é de esperar que haja embate e posições a serem afirmadas." 